\title{
Moral Education for Sustainable Development: Exploring Morally Challenging Business Situations within the Global Supply Chain Context
}

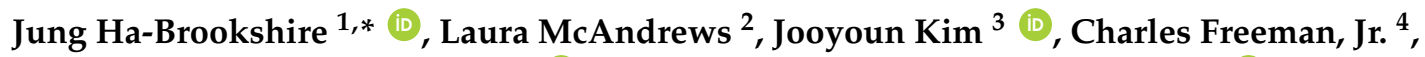 \\ Byoungho Jin ${ }^{5}$, Pamela Norum ${ }^{1}$ (D), Melody L. A. LeHew ${ }^{6}$, Elena Karpova ${ }^{7}$ (D), Lesya Hassall ${ }^{8}$ \\ and Sara Marcketti ${ }^{8}$ \\ 1 Textile and Apparel Management, University of Missouri, Columbia, MO 65211, USA; norump@missouri.edu \\ 2 Textile, Merchandising, and Interiors, University of Georgia, Athens, GA 30602, USA; lauraemc@uga.edu \\ 3 Textiles, Merchandising and Fashion Design, Seoul National University, Seoul 08826, Korea; \\ jkim256@snu.ac.kr \\ 4 School of Human Sciences, Mississippi State University, Starkville, MS 39762, USA; \\ CFreeman@humansci.msstate.edu \\ 5 Consumer, Apparel and Retail Studies, University of North Carolina at Greensboro, Greensboro, NC 27402, \\ USA; b_jin@uncg.edu \\ 6 Apparel, Textiles, and Interior Design, Kansas State University, Manhattan, KS 66506, USA; lehew@ksu.edu \\ 7 Apparel, Events, and Hospitality Management, Iowa State University, Ames, IA 50011, USA; \\ karpova@iastate.edu \\ 8 Center for Excellence in Learning and Teaching, Iowa State University, Ames, IA 50011, USA; \\ lesya@iastate.edu (L.H.); sbb@mail.iastate.edu (S.M.) \\ * Correspondence: habrookshirej@missouri.edu; Tel.: +1-573-882-6316
}

Received: 31 July 2017; Accepted: 11 September 2017; Published: 15 September 2017

\begin{abstract}
This study presents the need for moral development education of current and future professionals so they can help build sustainable companies and global supply chains. Grounded in Ha-Brookshire's moral responsibility theory of corporate sustainability, the authors explored a set of real-life business situations where business professionals experienced morally challenging dilemmas. The study was conducted within the context of the textile and apparel (TA) industry because of the global and fragmented supply chain nature of the industry. The real-life business situations were interpreted using Kohlberg's moral development stage theory. The results of in-depth individual interviews followed by three focus groups of industry professionals in spring 2017 showed that participants have experienced a variety of morally challenging business situations throughout their careers. This includes simple problems at the individual and firm levels, as well as wicked and complex problems at the industry and global levels. The study concludes that for TA businesses to be truly sustainable, professionals' moral ability is critical and, therefore, appropriate moral development education is necessary.
\end{abstract}

Keywords: moral development; moral education; corporate sustainability; business situations

\section{Introduction}

The need for sustainable development is well documented (in this study, we follow the definition of the United Nations' sustainable development that describes that such development must ensure the next generations will have access to resources to meet their needs and to take care of the people and communities while satisfying our current needs [1]). The textile and apparel (TA) industry plays a large role in sustainable development as it uses a variety of raw materials from agricultural products such as cotton and wool to synthetic industrial products such as polyester and nylon [2]. Subsequent 
product transformation then takes place in the global marketplace [3]. For example, U.S. grown cotton would be turned into textiles in China and then shipped to Vietnam for garment assembly before returning to the U.S. market for consumption [4]. In another example, wool fibers harvested in Australia might travel to Indian textile mills. Pakistani apparel factories will then use the fabric to produce apparel. Because of this complex, fragmented, and extensive global supply chain, ensuring sustainability throughout this product transformation process is extremely challenging [5].

One way to promote sustainable business decisions in today's complex market environment is to emphasize sustainability as a moral responsibility of all businesses within the supply chain. In the moral responsibility of corporate sustainability (MRCS) theory, Ha-Brookshire [5] argued that sustainability must be the key goal for all supply chain members and considered a moral responsibility to fulfill. The argument was grounded in the corporate personhood concept, in that all corporations are legal persons and, therefore, they bear a moral responsibility to the environments and society as all humans do [6]. Consequently, the author argued that all involved business members must be morally responsible to achieve truly sustainable supply chains in the global marketplace.

Throughout the global supply chain, businesses face a variety of morally challenging situations while pursuing corporate profits. For example, after a fire in a Bangladeshi apparel factory killed 1000 workers in 2013, major apparel retailers were faced with a decision: Should they stay in the country and work with local stakeholders to improve working conditions and living standards or look for manufacturing locations in other countries? From the financial profit perspective, leaving Bangladesh was a better choice. Nike and The Walt Disney Company left the country [7]. At the same time, Wal-Mart and H\&M committed to staying in the country and improving conditions in the industry [8,9]. Decision makers in this case must have an extensive level of moral ability as well as a macro-level understanding of global society. In another example, a fashion designer may face a choice between sourcing lower-priced textiles produced under poor labor or environmental conditions and higher-priced materials produced utilizing fair labor and environmentally responsible practices.

Today's TA professionals may face morally challenging problems in their work space, and these professionals play an important role in corporate moral ability when building sustainable businesses and supply chains; therefore, developing appropriate educational materials is critical for enhancing the moral ability of the current and future workforce. With respect to this goal, in this study, problem-based learning is especially useful and effective as it helps students learn as they "solve the many problems we face every day" [10] (p. 1). Students learn by solving problems in the context in which they occur and assessing multiple perspectives related to that problem [11]. As the first step in developing appropriate educational materials for moral ability for future TA professionals, the present study identified a set of real-life situations that could be morally challenging for professionals making business decisions. Throughout this paper, we refer to Kohlberg's [12] six stages of moral development theory. These stages were used to develop a set of real-life business situations that pose varying degrees of complexity and, therefore, require different levels of moral ability of the problem solvers. The TA industry was investigated in this research as it is one of the most fragmented and globalized sectors [3], providing rich contexts for a variety of morally challenging business situations across the supply chain as well as perspectives of different cultures.

\section{Literature Review}

\subsection{Sustainability Educaton in $T A$}

The topic of sustainability has been typically integrated into the TA curriculum as an additional course or an extra discussion to a TA course [13] rather than systemically integrated throughout the curriculum. Armstrong and LeHew emphasized the need for a holistic approach, aligning sustainability with any discipline and based on a scrutinized understanding of both the explicit and implicit implications of sustainable development of the TA industry [13]. Also, Leerberg et al. [14] reported on the educational efforts for sustainable apparel design at Kolding School of Design, where sustainability 
learning modules were integrated into a practice-based studio course and the theory-based design criticism courses. Through the courses, design students were challenged to consider various aspects of sustainable apparel manufacturing, including life cycles of materials, quality of design, function, aesthetics, etc. The authors [14] emphasized the importance of teaching responsible and sustainable design concepts, which will empower individual design professionals to make positive changes in their decision making toward sustainable design.

As the TA industry uniquely involves both technology and agriculture of raw materials, the field needs to explore additional morally challenging situations that have not been fully covered by other fields (e.g., organic farming, use of pesticides, genetically modified cotton, etc.). TA academicians and professionals also acknowledge the need to accommodate the breadth and depth of sustainability knowledge, including environmental regulations, supply chain complexities, ethical and social responsibility, etc. [2]. More recently, a team of TA educators developed an online educational portal that provides professional development resources from the science of climate change to its connection to the TA industry [15]. However, sustainability in TA curriculum, so far, is mostly addressed as supplemental rather than foundational due to several barriers such as content limitations, deficiency of scientific knowledge, lack of tools and strategies, and lack of student interest [2].

\subsection{Moral Responsibility Theory of Corporate Sustainability}

While previous efforts in sustainability have focused on specific content knowledge about how to improve sustainability goals, Ha-Brookshire's [5] MRCS theory offers new insights into the need for evaluating sustainability from the corporate moral responsibility perspective. According to the theory, sustainability is a moral duty for all corporations to fulfill and, therefore, all members of a corporation must abide by moral duties throughout the supply chain for any product to be truly sustainable. The logic is that a corporation acts as a person in the legal system (a.k.a. corporate personhood) [6] and, therefore, each corporation bears moral responsibilities toward society and the natural world as all people do $[6,16,17]$.

One of the key points in Ha-Brookshire's [5] MRCS theory is that members of corporations, whether they are cotton farmers in the U.S. or apparel factory managers in Bangladesh, must act morally responsible so the company and the entire supply chain can become more sustainable, thus fostering a greater sustainability in the TA industry. It follows that there is an immediate need to train and educate the future workforce to be morally responsible so professionals are prepared to evaluate, develop, and implement various morally responsible corporate sustainability activities. However, little is known about how industry professionals deal with sustainability-related business decisions from the moral responsibility perspective and how they negotiate and solve the conflicts between short-term, business-focused goals and long-term social or environmental goals.

\subsection{Need for Moral Development Education for Corporate Sustainability}

The gap in our understanding of difficult situations that industry professionals face from the moral perspective creates a challenge for educators: How can we prepare future professionals to lead the industry focusing on sustainability? Without an appropriate level of moral development, the graduates may not be able to exercise their moral ability and, therefore, according to MRCS theory, truly sustainable TA supply chains would be difficult to achieve. Consequently, how can we teach moral ability?

For moral development education, literature suggests that three key areas of moral ability must be tackled: moral cognition, moral affect, and moral behavior [18]. First, moral cognition education focuses on cognitive processes such as reasoning and evaluation. In fact, after examining college students' ethical and intellectual development, Perry [19] found that through effective education students were able to move away from a dualistic worldview, recognize multiple perspectives, and take a contextual approach to judge adequacy of moral values. Similarly, Passarella and Terenzini [20] showed that major changes in moral cognitive processing indeed take place during the college period. 
Therefore, the authors Passarella and Terenzini [20] argued that proper moral development education during college years is necessary to help students develop their moral ability.

Second, moral-effect researchers focus on emotions. Empathy is known to be the primary moral emotion, and the researchers suggest education is key to enhance college students' empathy toward others, society, and the world [20,21]. In this light, Noddings [22] showed that peers and authorities can help students develop moral emotions through modeling, dialogue, practice, and confirmation.

Finally, with regard to moral behavior, Bandura [23] argued that all behaviors are learned through observing others' behaviors, following role models, or watching consequences of desirable or undesirable behaviors. This is the gist of social learning theory [23]. In this light, Astin [24] found that students' values, beliefs, and aspirations indeed changed in the direction of the dominant values, beliefs, and aspirations of the peer group during the college years and, therefore, having appropriate peer role models and cases is critical for moral behavior development of undergraduate students.

\subsection{Kohlberg's Moral Development Stage Theory}

Swaner's [18] research indicates that through education, individuals can learn moral ability, including moral cognition, moral affect, and moral behavior. A useful framework of moral ability was created by Kohlberg [12] who theorized that humans progress through six stages of moral development. He proposed that at each stage a person would be able to respond to different types of moral dilemmas using different levels of reasoning. Although his theory mainly focuses on children's developmental stages of moral development, one could argue that this theory can be applied to the moral development of professionals learning new workplace principles or norms. Indeed, many professions have their own codes of conduct, and college students and young professionals are required to learn discipline-specific principles and norms.

Kohlberg's [12] six stages of moral development are classified into three levels based on the relation of the self and moral expectations of society. At the Pre-Conventional Level 1, moral rules are external to the person facing moral dilemmas. That is, moral rules and expectations are given to the person who must follow these rules. The person does not need to figure out whether a behavior is good or bad because the decision was already made by external entities. Kohlberg's [12] first two stages form Level 1. Stage 1 is referred to as heteronomous morality with egocentric point of view and moral realism. At this stage, a person is egocentric - he or she cannot differentiate his or her perspective from the others' perspectives. Moral rules are given from the outside or from above. Stage 2 is individualistic, instrumental morality focusing on a concrete-individualistic socio-moral perspective. At this stage, moral relativity emerges and the person now can see all interests are equally valid. Therefore, equitable agreement with others satisfies one's needs, and moral justice could arise when instrumental exchange of favors gets established.

At the Conventional Level 2, a person is able to internalize the expectations of society or the community [12]. That is, the person is aware of and expected to follow social norms, and he or she does so because the goal of moral reasoning at this stage is not to upset the whole community, such as business unit, firm, or even the industry. Kohlberg's [12] Stages 3 and 4 are associated with Level 2. Stage 3 refers to interpersonal normative morality with a focus on shared norms within the community. The individualistic perspectives are now constructing a third-party perspective that emphasizes relational values and norms-moral values are now viewed as "do unto others as if the others were the self" [25] (p. 73). Stage 4 is described as social system morality in which an individual can take on the perspective of a generalized member of society. That is, the sense of "us" established in Stage 3 is now expanded to a larger society and, at this stage, the needs and values of the social system and the want to support social institutions become critical for moral reasoning.

The Post-Conventional Level 3 includes the last two stages, 5 and 6. At this level, the personal rules are clearly identified rather than given by an authority [12]. When the social norms and the person's rules are not consistent, the person at this stage is able to challenge the social norms and try to change the inferior social norms for the greater population. Stage 5 is called human rights and social 
welfare morality, in which an individual becomes a rational moral agent aware of universal values in a moral society. Finally, Stage 6 is referred to as morality of universal, reversible, and prescriptive general ethical principles. That is, at this stage, a person is able to integrate various justice operations into a self-reflective mode of moral reasoning and have a commitment toward justice for all, often exercising prescriptive role-taking and endorsing intrinsic worth, value, and dignity of all human beings.

\subsection{Research Gaps and Objectives}

Following Kohlberg's [12] theory of moral development, the first step in helping individuals to increase their moral ability is to identify and categorize real-life morally challenging business situations. These real-life business situations could be used as the basis to create appropriate educational materials, especially problem-based learning materials. This is particularly important for promoting corporate sustainability and a sustainable supply chain in the TA industry because of the extensive breadth and depth of sustainability knowledge required for TA professionals [2] to make morally sound decisions. A collection of real-life situations could also help when developing a comprehensive educational module for students' moral development throughout their college career. Therefore, the study findings will help address the lack of specific content representing TA professionals' everyday morally challenging situations, which then could help identify appropriate educational techniques and build effective educational materials. Consequently, the purpose of this study was (a) to identify real-life morally challenging business situations, which TA professionals have experienced or are currently experiencing and (b) to categorize these situations into different complexity levels that would require various degrees of problem solvers' moral ability, as described by Kohlberg [12].

\section{Methods}

\subsection{Two-Step Approach}

We utilized a two-step approach: (a) in-depth individual interviews and (b) focus groups. Due to the exploratory nature of the study, in-depth interviews were chosen because they allowed the researchers to best capture participants' views through their own words and experiences rather than assuming elements of a new, little researched topic [26]. In addition, qualitative investigation allows researchers to understand relationships among nuanced pieces of a process so that a more complete picture or theory can be formed [26]. As topics of moral responsibility for sustainability and morally challenging situations can be sensitive, an interview allows for an open-ended, conversational tone to put participants at ease. The goal of the interviews was to gather as many diverse morally challenging situations as possible.

Next, a focus group is a useful tool when researchers want to see group interactions among the participants [27]. An open and free discussion of a topic by a group of diverse experts enables a deeper understanding of the essence of related experiences and allows researchers to better capture the participants' views, opinions, and attitudes. In this study, the focus group was designed to (a) validate and explicate the stories that were collected during the interview stage; (b) enrich the previously captured real-life situations; and (c) gather any additional morally challenging situations that could have been missed during the interview stage.

\subsection{Participants}

Using criterion sampling to ensure the research goals were addressed [26], the participants were recruited for their professional experiences in the TA industry. Professionals who are retired or at near retirement were targeted not only for their extensive experiences but also their ability to share more sensitive stories related to morally challenging situations without any blowback or threat from their current or past employers. We also targeted people who work with extensive groups of people within the TA industry to gather as many real-life situations as possible. Due to the sensitive nature of morally challenging stories, we also sought professionals within the research team's professional network to 
allow for researcher-participant trust. Finally, we ensured that participants represented a variety of supply chain functions, from design and market research to sourcing, merchandising, and retail.

A total of 14 one-on-one interviews were conducted by six researchers. Two participants were in cotton farming, two in yarn manufacturing, two in accessory manufacturing, one in product development, two in design, three in global sourcing, two in merchandising/retailing, and one in marketing communication. The focus group included 10 participants. Five of them were also interviewed in the earlier phase, and the other five were new to this project. The same criteria for sampling were used. The focus groups were conducted in Atlanta, Georgia, where the research team members and 10 professionals met and discussed the outcomes of in-depth interview results and additional business situations deemed to be morally challenging. Table 1 shows the characteristics of the 19 study participants.

Table 1. Descriptions of the Study Participants.

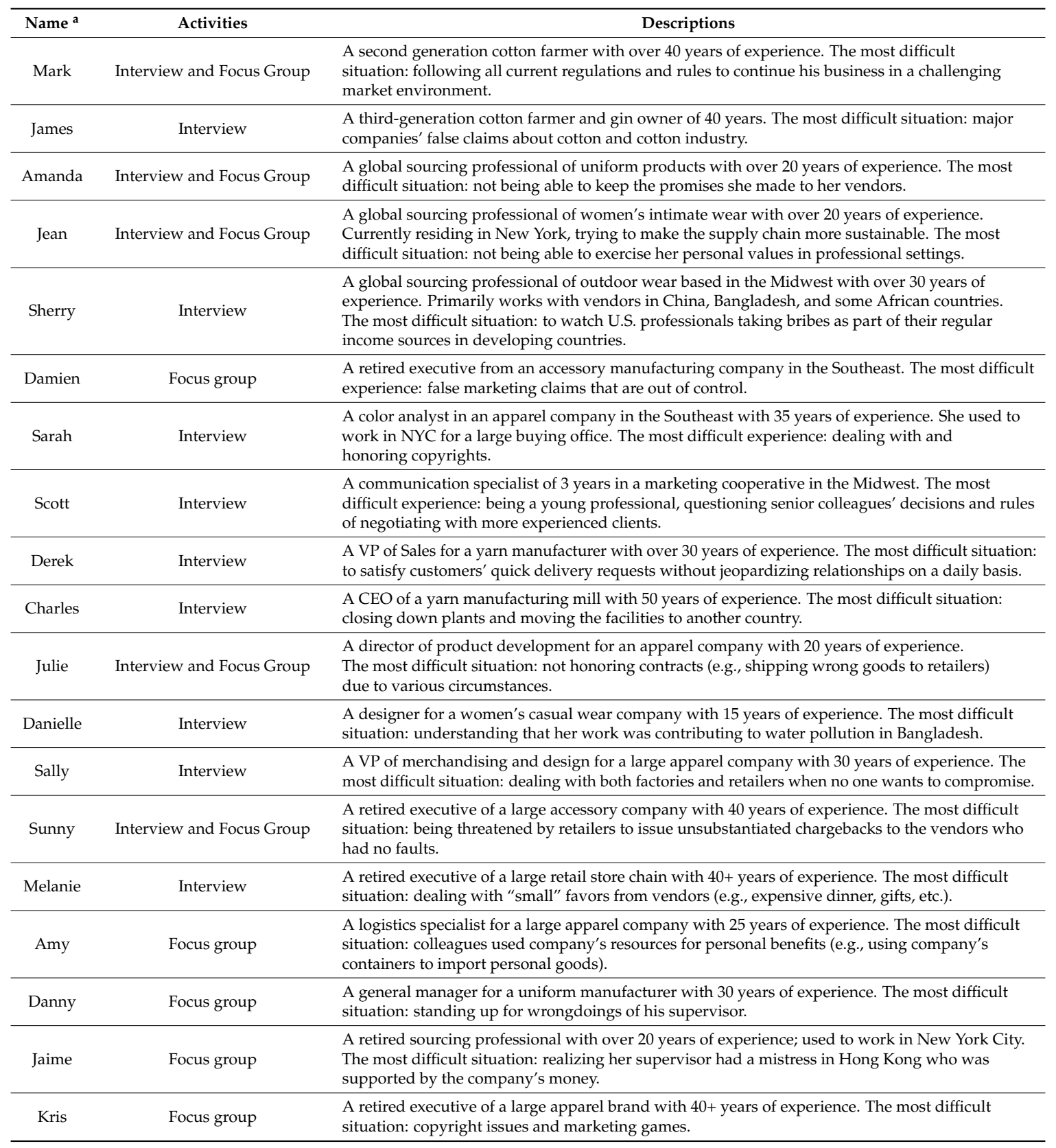

${ }^{a}$ All names here are pseudo names. 


\subsection{Data Collection and Analysis}

Interview. With the approval of the Institutional Review Board, interviews were conducted in spring 2017. Each interview took approximately 50-80 $\mathrm{min}$, and the conversations were audio recorded and transcribed for analysis purposes. Demographic questions were asked for the purpose of clarifying the respondents' expertise in the industry. Interview questions started with positive aspects of their professional experiences, such as "What do you like most about your role in the industry?" Gradually, the questions addressed more challenging situations they may have experienced or heard from others, such as "What were the tough choices that you made every day or that you have made recently?" "Tell me of a time when you made some difficult decisions". "What worries you the most about the future of the industry?" Or, "When was the last time you faced a decision that did not sit well with you? What was that about?"

Focus group. Prior to the focus group, the research team members analyzed and interpreted the interview data. The results of these preliminary findings were then shared with the 10 industry professionals who participated in the focus groups. Three focus groups were formed, with each group including 3-4 professionals and 2-3 research team members. Each group was tasked with reviewing the interview preliminary results, validating them as real-life situations, clarifying and adding more details to the situations, and seeking additional situations. This process took approximately three hours. The results of each focus group's discussion were then shared with the entire team of the participants and researchers, who discussed the overall themes, commonalities, and differences. This process took an additional two hours.

All focus group participants agreed that the situations collected through in-depth interviews were consistent with their experience within the industry, whether through direct personal experience or observation of colleagues' experiences. Next, participants emphasized the importance of creating new educational opportunities to enhance college students' and/or young professionals' moral ability. In fact, one of the participants, Damien, shared "I would love to be a part of this project going forward. This is so important, and I wish I had this education before entering the workforce". Finally, building on each other's stories, participants provided detailed accounts of additional situations with more specific contexts, rich descriptions, and details, which validated and expanded the interview data.

Rapport and trustworthiness. Throughout the interviews and focus group activities, rapport between the research team and the participants was pursued, as it would help minimize social desirability bias in responses. Some participants made this clear by indicating the private nature of what they were saying: "You won't share the names, right?" or "This story is just for you, guys." Other participants were drawn to the topic itself, indicating their willingness to share openly, which was reaffirmed by stating they were highly interested in seeing the study once it was finished. All participants showed their strong interest in this topic by seeking future updates on and input to this study's topic. The thick descriptions and quotes provided in the findings below also indicate that participants were comfortable speaking openly on the sensitive topics, increasing the trustworthiness of the study findings [26].

Interpretation. Both interview and focus group data were interpreted by the entire research team. Each story was discussed and assessed for the degree of complexity and the level of moral ability required by a problem solver. Throughout this process, two major theme categories emerged across the TA supply chain: context and complexity. Context ranged from individual or firm level to industry or global level. Complexity ranged from simple to very complex and difficult situations. Each story was then placed within the $X-Y$ axis plot, helping the research team understand the different levels of moral challenges that professionals may face, which might require a different range of moral abilities (Figure 1). These stories were not specific to any particular area of the TA supply chain; rather, they were consistently present across the supply chain members.

The $X$-axis shows the varying degrees of morally challenging situations, from simple, easy-to-solve problems on the left side (labeled simple) to complex, difficult-to-solve problems on the right side (labeled wicked). Simple problems usually require simple solutions, and most of the professionals are able to address the problems without deeper analysis or extended considerations. At the same time, 
wicked problems, being highly complex, require consideration of multiple interdependent factors [28] and, therefore, every wicked problem is unique and the solutions may not be inherently right or wrong; rather, the solutions may create other problems [29].

The $Y$-axis indicates the degree to which a situation takes place from the individual or firm levels up to the industry and global levels at the top of the chart. In this study, individual-level contexts were labeled as such because they typically affected only one person and required actions of the professional to solve such situations. Firm-level contexts focused on a specific firm's internal situations in which the firm had the power to make decisions on future actions. The industry-level contexts were deemed to deal with business conditions that cannot be fixed or solved by only one firm due to the presence of an industry-level force or conditions. Finally, the global-level contexts were identified as morally challenging situations created by macro-level forces, such as cultural differences, domestic and/or foreign regulations, or characteristics of the dominant economic paradigm (e.g., emphasis on profit and perpetual growth).

\section{Interpretation}

Through the evaluation process of morally challenging situations identified by participants, all situations were classified across the two continuums of complexity and context (Figure 1). Most situations identified as simple were positioned in the lower left corner of the X-Y plot, suggesting individual level problems tend to also have a lower degree of complexity. At the same time, wicked situations were positioned in the upper right corner of the plot due to the complex, interdependent nature of the situations as well as the inability of one professional or a single firm to implement a solution. Within the aforementioned structure of the study data, the next section is organized into the five categories of morally challenging business situations shared by the study participants: (a) Individual-Simple; (b) Individual-Wicked; (c) Firm-Simple; (d) Industry-Wicked; and (e) Global-Wicked. Figure 1 describes the study findings based on the context and complexity of the morally challenging situations that emerged from the study data. Each box will be explained in detail in the next section.

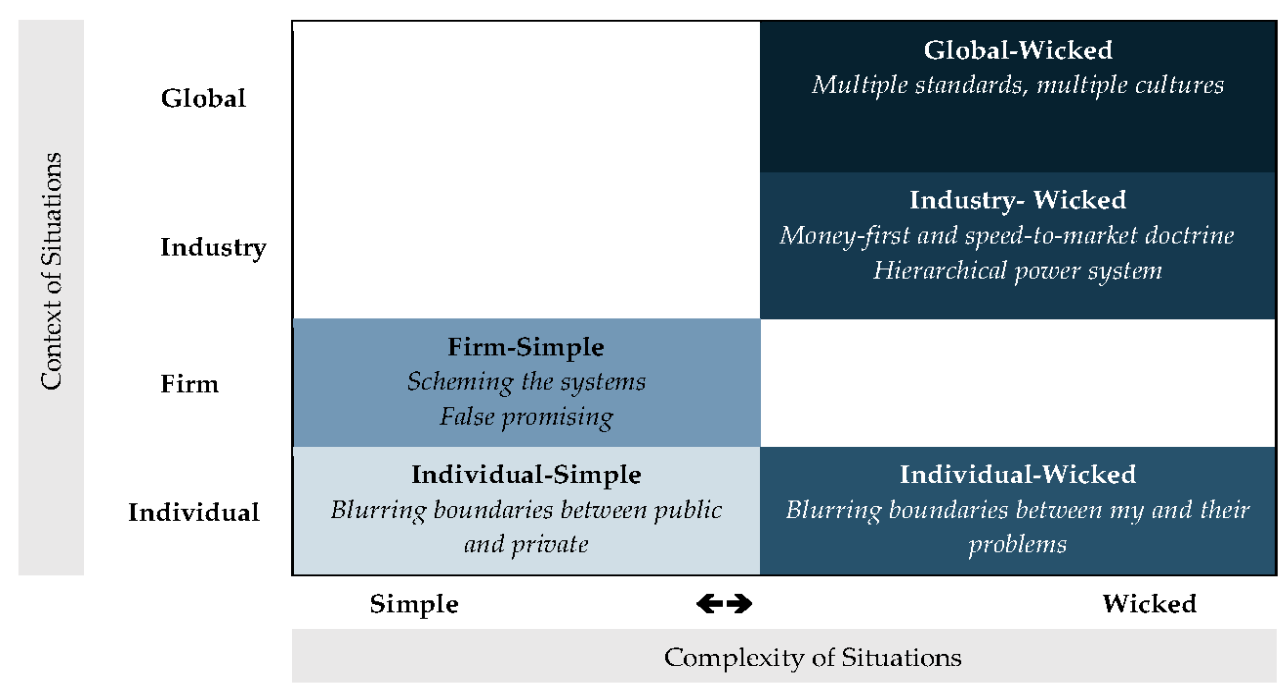

Figure 1. Research Categories of Morally Challenging Real-Life Business Situations.

\subsection{Morally Challenging Situations: Individual-Simple}

Blurring boundaries between public and private. At the individual level, most situations that the study's participants experienced or witnessed during their career were related to blurring boundaries between private and public goods. Two key situations emerged within this theme. First, there were many examples of an employee using the company's properties for personal purposes. For example, paper, staplers, envelopes, and other products were taken by employees from the company. This was 
a common situation shared by all participants. Although these situations seem almost harmless to the company, Amy, a logistics specialist, shared "You never know when it is too much". She noted that she witnessed people importing sample garments without marking them as samples. Yet, they were imported as if they were samples, and therefore, no duties were paid. The imported samples, however, have commercial value and people can have them for their personal use after they served a business purpose. Furthermore, Amy's divisional manager had included personal goods (kitchen sinks, ceramic tiles, and porcelains for his house remodeling project) in a container full of clothing imported from Mexico without declaring these personal products to U.S. Customs to avoid duty and transportation costs.

Similar to stealing a company's tangible properties, one may steal intellectual property as well. Kris, a retired fashion executive in product development and design, shared that he often saw young designers and design interns copying others' designs or artwork without considering copyrights. Taking images from online sources and using them as if they were their own without appropriate payment or acknowledgement is very common, and the problem is that the individual who is doing so often does know that this is a form of stealing. Sarah, who used to work in a buying office in New York City, shared her situation:

I see that your scarf is a print, it could have possibly been purchased from a print studio by the scarf company and paid a very hefty price for one pattern, which would be somewhere in the neighborhood of $\$ 600$. Pretty pricey, significant. At a meeting with the print artists, one of my print designers comes to me and says "Someone asked me to make a copy of this print, and I know I was not supposed to do this. What should I do?"

Whether it is a physical product (e.g., stapler or garment sample), physical space (e.g., container space), avoiding regulations (e.g., not paying import duty), or idea (e.g., design or artwork), participants shared that stealing is a common occurrence in the industry. This type of conduct could be simply solved if the individual decides not to do so. These types of problems are simple enough so that even people in Kohlberg's [12] Stages 1, 2, or 3 could solve them. Stealing of any sort has to be one of the fundamental violations of a sustainable supply chain because, after all, the goal of sustainability is to leave something for future generations so they can thrive on this earth. If our generation "steals" all the resources to meet its needs today, the existence of future generations would not be possible.

\subsection{Morally Challenging Situations: Individual-Wicked}

Blurring boundaries between my and their problems. Although some situations required only a personal decision, there were some individual-level problems where professionals seemed to question whether it was their own or another's problem to solve. These situations were classified as individual-wicked problems. For example, Sherry, a sourcing professional, shared that her former colleagues and supervisors took cash bribes, or "rebates," from foreign manufacturers in exchange for future business orders. She knew it was wrong but she did not do anything about it. In fact, she was not sure if her whistleblowing would help solve the situation or not. Therefore, the conclusion was that if it will not fix the problem, stay quiet. According to Sherry's assessment, the solution to the problem is in the hands of the individual who accepts the rebates, so there is nothing she can do to solve it, making it a wicked problem for her. Sherry vividly describes the culture of local liaison offices in China, Bangladesh, and other developing countries:

Rebate means an agreement, no matter how many orders I give, you have to meet the price, quality, whatever that is. But every piece I give you, you give me back 50 cents, personally. It becomes $\$ 40-50 \mathrm{~K}$ per year quickly. And you have to find a way to carry the cash to me because I don't want that amount shown in my account. I was, like, why are you doing this? They [factory owners] said they have to give this to the buyer for future business. Nothing I can do. 
Similarly, Jamie, also a sourcing professional, shared that she witnessed her former supervisor letting his mistress stay in an apartment the company leased for employees' use in another country. At the same time, Jaime had a close relationship with her supervisor's wife. Because this was a personal matter, rather than professional, Jaime was not sure if she needed to do something about it. As long as her supervisor performs his work well, then she thought there was no need for her to get involved.

Both examples are wicked situations for an individual to solve because many factors are inter-related. Both Sherry and Jaime were uneasy about the fact that they were not able to exercise their own personal moral values to resolve the situations. They were concerned that they may lose their jobs or get bad recommendations for future employment if they blew the whistle. However, leaving the situations the way they were did not sit well with either participant. Solutions were needed but it was difficult for an individual to act upon them. These types of problems could easily be extended to more specific corporate sustainability activities. Someone might bribe compliance auditors or witness the bribing. Others may see someone cheating on tests or audits. Yet, if no one raises the issues and brings them into the light, the situations would continue, making the supply chain unsustainable. These types of problems require a more advanced level of moral ability and can be classified as Kohlberg's [12] Stages 5 and 6 . These situations require an individual's courage to stand up when necessary.

\subsection{Morally Challenging Situations: Firm-Simple}

At the firm level, two major themes emerged, both of which appeared to be relatively simple situations to solve: (a) scheming the system and (b) false promising.

Scheming the system. This theme describes a variety of ways in which a company creates a culture or standard procedures to scheme the existing systems or rules. That is, this strategy seemed to be beyond an employee's individual behavior; rather, it was pervasive at the company level, with the goal of maximizing financial profit. For example, according to Jean, a sourcing specialist, some companies encourage their sourcing personnel to pre-announce the audit schedule to a factory so that the factory could prepare ahead of time and have a better chance of passing the audit. The principle here is that the audits must be done without any announcements so that the auditors can inspect the factories in their every-day usual operational mode. However, a quick phone call with the actual date and the auditor's name would help the factory to prepare for the audit.

Kris, a former designer and product developer, shared that her company had a specific way of developing new products. That is, her team goes out to the marketplace, buys popular products, brings them back to the office, reverse-engineers them, then returns the products for refund. Meanwhile, her team finds a way to replicate those products without any costs or R\&D investment. Sunny, a former divisional merchandise manager for a major retailer, shared that she was often under pressure from the upper management to manipulate the numbers related to cost of goods sold in order to show higher initial markup numbers. Sometimes, the goal was to show "better than expected" margins to outside stakeholders, when, in fact, they were not.

Similarly, Jaime shared that she was in a situation where a Chinese factory owner asked for a half-million payment to be split into two accounts: his personal account in Switzerland and the company's account in China. She was told that this is how the factory works in handling finances and Jaime's company was not responsible for what the factory does with the money they earn. Sherry, a long-time sourcing manager, also shared that many sourcers are faced with two different costs from the vendors in countries such as Bangladesh or Cambodia: one represents the cost of manufacturing goods in compliant factories, whereas the other represents the cost of producing the exact same goods in factories that are not compliant. To increase profit margins, some companies pressure sourcers to give a portion of the business to the compliant factories at a higher price but to place the majority of orders in non-compliant factories at lower prices. Meanwhile, the sourcers could use the compliant factory as their main suppliers and show the world that they are compliant with labor and environmental practices. Sherry explains, "They [factories] are not really up to the standards we want them to be but they give you $\$ 2$ cheaper. So what's your decision?" 
All of these situations were interpreted as deliberate ways a company can scheme the system. By doing so, other companies who are following the rules and regulations are suffering from unfair competition. Charles, a CEO of a U.S. yarn manufacturer, shared his experience with his competitors' cheating on rules of origin to save money on import duties:

So it's not really that my competition is cheating on this rule of origin on the yarn. It's actually some of my potential customers playing games, like, import cheaper, way cheaper yarn and made of fabric but they still claim it's made-in-the-U.S. yarn or made-in-the-region yarn. So that really gives all those players who wants to work by the rule, they get to really suffer because of that. In reality, they have to fight with those people who don't play by the rules.

Indeed, companies know which games to play and how to play them. The problem is that if the majority of companies focus on maximizing their own interests and conducting or condoning morally questionable behavior, then greater sustainability within the entire supply chain will be unattainable. A simple solution would be for companies to follow rules and regulations-in this case, rules of origin. Unfortunately, companies sometimes bend the rules and manipulate the system to get what they want. These types of problems, at the firm-level context and simple level in terms of complexity, appear to be similar to the concrete-individualistic socio-moral perspectives that the individuals in Kohlberg's [12] Stage 2 would have. That is, as long as I or my company benefit from bending rules a bit, it is okay.

False promising. A second theme under the Firm-Simple category includes situations in which companies promise one thing but deliver another. Damian, a former executive in accessory manufacturing, shared that his company would show great samples to potential buyers (promising one thing) but then substitute materials, using cheaper raw materials in production without informing the buyers (delivering another). Amanda, a product developer, shared a similar story: She would ask U.S. vendors to make all required samples and to spend hours developing new products, but then her company would push her to find cheaper overseas vendors and share the techniques and strategies that were developed by the U.S. vendors. Both situations illustrate a firm's false-promising strategy.

An apparel product developer, Julie, shared a situation related to this theme on a more advanced level. She once worked with a Miami-based intermediary that represented factories in South America. Her company had been making payments to the intermediary each time an order was fulfilled. However, one day, her company received a lawsuit complaint from a factory in South America for non-payment. Later, Julie's company discovered that the intermediary had not been paying the factory, even though they had assured that the factory was paid for the produced goods. In this case, the intermediary company was false promising and not delivering to both parties for their own financial gain.

Another example that Julie shared was that her factory in Pakistan was supposed to produce brushed flannel pants. However, the final products were not brushed and they did not even look like flannel pants. When this problem arose to Julie's attention, upper management decided to ship incorrect goods to the retailers without telling them about the issue. Of course, this resulted in a larger problem when the retailer caught the mistake leading to a huge financial loss for her company and damaging the trust of the retail customer. This problem could have been a less complicated fix if the retailer was informed about the product shortcoming. Instead:

So, we went ahead and shipped it [to the retailer]. So, it essentially went right to their retail stores. So, we shipped it to them and we got nailed for it and so we took it all back. ( . . ) . I'm sure we still have some of it in our warehouse! It was such a large order. So, they [retailer] don't pay for it. Then we're stuck with all these products, and we already paid the factory (Julie).

All of these stories share the theme of false promising to vendors, factories, or even the public with the hope that nobody would notice. Even if caught at some point, these companies were able 
to profit from the morally questionable behaviors many times, providing enough financial resources to weather the negative consequences, as reported by participants. Similar to the previous theme, all of these situations could have been solved easily. After all, falsely promising to someone, knowing that they cannot keep the promise, is wrong and companies could prevent these situations internally. Again, this type of problem is similar to the concrete-individualistic socio-moral perspectives that the individuals in Kohlberg's [12] Stage 2 would have. That is, as long as I or my company benefit, it is okay.

\subsection{Morally Challenging Situations: Industry-Wicked}

At the industry level, most situations were wicked problems, which were difficult if not impossible to solve due to the complex nature of industry characteristics that are beyond individuals' or firms' control. Two major themes emerged: (a) money-first and speed-to-market doctrine and (b) hierarchical power system.

Money-first and speed-to-market doctrine. An overarching trend in the industry was described as "the money first" and "speed to market" by the study's participants. Both of these themes seemed to relate to the characteristics of Kohlberg's [12] Stage 4, at which individuals accept widespread social norms without the courage to speak up for justice. This trend seemed to create distinct morally challenging business situations in the global TA industry.

Zealous marketing is one aspect of this trend, where companies do not hesitate to overstate the functions and services of their products without substantiated evidence with the hope of increased sales and profits. Because of the flood of new products coming to the marketplace every day, many unsupported product claims persist without legal or negative consequences, fueling even more unsubstantiated marketing statements, as expressed by Damien. Amanda pointed out that the market is flooded with false claims, especially for products with sustainability claims, such as using the word "natural" in a baby wipes brand when the product contains non-natural ingredients, or a "southern shirt company" brand using a cotton ball on its logo when the main raw material of the shirt is $100 \%$ polyester.

As a second-generation cotton farmer of 50 years, Mark shared his experience with cotton industry becoming the victim of zealous marketing. Mark does not agree that cotton clothing is less sustainable than polyester-based clothing even if polyester can be recycled more easily. In his view, polyester fibers are very harmful to the environment through microfiber shedding during laundry; therefore, he disagrees with companies' claims of polyester products being sustainable:

Nike is the same way, Adidas, Nike. And I think Adidas and that group needs to make a moral decision as well because the polyester that they are using is internally getting into the food chain and I don't know if you know, I'm sure you know a lot about that, the microfibers are breaking down and they get into the water which in turn are getting to your fish, into your food system. I think that's a moral decision.

James, a third-generation cotton farmer, also mentioned that the U.S. cotton industry is being misunderstood by Better Cotton Initiative's (BCI) marketing claims. BCI claims that its goal is better global cotton production for the environment. According to James, $\mathrm{BCI}$ 's requirements are so low that most U.S. cotton farmers not only meet but surpass the standards. However, $\mathrm{BCI}$ requires fees to be certified, incurring additional costs to the farmers. As a result, despite growing it in "better" ways, James' cotton is not labeled as BCI and cannot be used by major athletic brands such as Adidas. For example, in 2015, Adidas indicated that over $43 \%$ of its cotton products used BCI cottons [30]):

$\mathrm{BCI}$ has certified emerging countries, less developed countries whose production practices are far, far, far below ours. They use chemicals, insecticides, herbicides that are banned in the US. BCI has been going in and basically blindly certified some of these countries for small and one family operation where one person has an acre or two. They are not at the commercial scales. BCI's message is wrong. 
The TA industry's pursuit of the speed-to-market strategy creates another set of morally challenging business situations. Jean, a sourcing professional, confessed that sometimes she has difficulty sleeping at night because of the potential quality issues of the products her company just delivered to retailers. Because of the time pressure, the company has to cut down the lead-time by skipping required quality tests. Similarly, labor compliance audits are sometimes skipped because of the time requirement, and she wonders if the factory conditions are safe and workers are being paid appropriately. With the whole industry in the race for fast delivery, all participants agreed that product quality and often manufacturing conditions are being jeopardized. As Derek described it:

That's one of the conversations I face on a daily basis with A-list customers (top buyers). Customers come in and say you got to help me, this came up and that came up. We have to have this yarn in 3 weeks or 4 weeks. Meanwhile, I'm quoting 6 weeks because I have other orders in line. In that case, you either lose that customer, or take the customer's request and make everything bulge. And now, there is this domino effect, and if the business stays like this, it goes on eternally so there's just no catching up. So there's a moral decision with that.

Hierarchical power system. Many of the morally challenging situations shared by the participants attributed the problems to the inherent nature of the industry, which has a rigid hierarchical power structure. TA supply chains are buyer-driven [3]; retail buyers have the strongest power over suppliers, and this power dominates any buyer-supplier negotiations for costs, delivery time, product quality, and working conditions. A shared understanding behind a chargeback is that large retailers are so powerful that they can ask for chargebacks from vendors whenever they do not meet their earning goals. Essentially, retailers want a certain level of profit margin by the end of each season, and if that goal is not met, suppliers pay the difference to retailers in order to continue business in the future. To ensure this practice, some buyers "withhold" payment or even "over-collect" money from the suppliers. Saks Fifth Ave, a luxury department store chain based in New York City, and Dillard's, an Arkansas-based retail chain, were accused of unsubstantiated chargebacks [31]. Saks Fifth Ave confessed the "improper collections of vendor markdown allowances" and paid back US\$21.5 million to the vendors in 2005 [31]. Damien echoed this industry trend and stated that the mentality of the industry is that:

The margin [is the key]. Sent through [issued] markdown paperwork to one of our suppliers. We charged back $\$ 5000$ for a markdown which they [suppliers] didn't agree to or will agree to. But, we just did so just to get the targeted margin for that quarter.

This trend is still present in the global supply chain. Sunny, a former VP of sales and merchandising in a large accessory company, was often directed to issue illegal chargebacks or to manipulate books:

They [her company's retail buyers] made them [suppliers] pay money for markdowns or those kind of things that wasn't in the vendor's best interest. And a lot of times I had bosses tell me to do illegal things and write chargebacks to a manufacturer that didn't really owe me any money. I never did anything illegal, but I was asked to several times, but make the phone calls to say this is what I'm doing to you. I'm dropping your line, marking your line down, you know, those kinds of things the manufacturer didn't want you to do but you needed to do to get your number.

Julie further stated that intermediaries, who are making connections between foreign manufacturers and U.S. retailers, continue to exercise their power over the factories and can threaten with potential order cancellation, markdowns, and disconnection of the relationship to gain better costs or delivery schedules. Young employees in this industry are told "it is what it is" and directed to "do as you were told," signifying a lack of empowerment among TA professionals. Damien summarized this notion, identifying wicked problems that the industry as a whole is facing: 
But sometimes you're the decision maker, so you are not influenced by somebody else, but some people, some companies, for example, the leader, the top executive has the mindset of "Let's do it quickly, no matter what". If a leader has done that, then people on a limb may think "Hey, I can do that because my leader, my boss, tells me I have to do that no matter what, then I can do under the table stuff" [referring to receiving bribes].

\subsection{Morally Challenging Situations: Global-Wicked}

Multiple standards, multiple cultures. All of the aforementioned situations become even more complicated when they take place in a global environment. The situations raised in this theme coincided with Kohlberg's [12] sixth stage-individuals' global moral points of "justice for all". Different countries have different cultures, norms, and regulations related to copyrights, bribes, gender relations, ageism, and even the meaning of work. For example, as Jaime pointed out, in Russia or Ukraine, without bribing highway police or Customs officials, no trucks or goods will travel across the national borders. It is wrong to bribe anyone in the U.S., but it is a necessary business transaction in some countries. Similarly, countries have different regulations on wastewater, air quality, or any other environmental regulations. Therefore, a standard that might be satisfactory in one country might not be acceptable in another, or vice versa. While managing this type of multiple standards, some might choose to follow the lowest requirements while others might choose the highest standards. With the money-first doctrine dominating the industry, many companies choose the lowest requirements across the globe, creating multiple layers of bureaucratic procedures.

In Bangladesh and India, culturally, men have authority over business decisions that women do not, according to Jaime. Therefore, the gender dynamics between men supervisors and women workers on the factory floor are something that a buyer must be aware of to ensure all workers feel safe and free at the factory. For example, Jaime shared that she once worked with a factory in India, which was completely compliant with codes of conducts, including on-time payroll payment to their workers. However, she found out later that in that part of India, women are not allowed to have a bank account without a male supporter, usually their father or husband. Therefore, women essentially had little control over their salary and money was paid to and spent by their male supporters. In this case, checking whether the factory pays them on-time in the right amount is less important for these women's true well-being. Rather, how much freedom and control these women could have over the money that they earned might be more important to track. Even in developed countries, such as the U.S., questionable gender dynamics are present, as illustrated by Sunny's example, "Women executives are expected to belong to the 'good-old-boys' club to advance their career."

The meaning of work could vary in different societies. For example, Jean shared that, in China, migrant workers in factories travel long distances to gain employment and earn money to support their families back home. These workers want to work more than 40 or even $50 \mathrm{~h}$ a week because, living in a factory-managed dormitory, they want to work longer hours to earn more money as quickly as possible so they can return home to be with their families. However, retailers, who do not want to be accused of workers' exploitation, are not willing to make an exception because consumers in the developed countries do not understand the reality of Chinese workers geographically being separated from their families. In Jean's opinion, this no-overtime-rule must be mindful of local contexts to truly help the workers it intends to protect. All of these situations reflect the wicked nature of problems that TA professionals may face on a global scale, which include multiple standards and multiple cultural expectations.

\section{Conclusions}

Building on Ha-Brookshire's [5] moral responsibility of corporate sustainability theory, the study presented the need for moral development education for current and future professionals so they can help build sustainable corporations as well as sustainable global supply chains. Following core suggestions for using problem-based learning, the research team identified a set of real-life 
business situations where professionals may experience morally challenging dilemmas. This is the first step in gathering and understanding the contexts and multiple perspectives of morally challenging problems that TA professionals face every day. Given the most globalized and fragmented supply chain characteristics, the TA industry was used as the context of the study, and the real-life business situations were then interpreted within Kohlberg's [12] moral development stage theory, which suggests that different levels of moral abilities are required for different levels of complex moral situations. The results of 14 in-depth interviews and three focus groups with 10 professionals showed that throughout their careers they have experienced various morally challenging business situations ranging from simple to complex. The simple problems generally impacted the individual (i.e., blurring boundaries between public and private) and the firm (i.e., scheming the system and false promising). The wicked and complex problems generally involved the industry (i.e., money-first and speed-to-market doctrine, and hierarchical power system) and global (i.e., multiple standards and multiple cultures) levels.

The findings of the study have several contributions and implications. First, the study findings do support Ha-Brookshire's [5] moral responsibility of corporate sustainability theory, in that various corporate sustainability efforts depend on its employees' moral behavior. That is, even if a firm requires sourcing products from compliant suppliers, if a sourcing professional schemes the systems and gives a prior notice to a factory before an audit, then the firm's efforts toward a sustainable supply chain would not be materialized. Therefore, the findings emphasize the moral responsibility aspect of corporate sustainability efforts. Without professionals' moral judgment and behavior, the goal of sustainability may not be achieved, echoing MRCS theory. Therefore, further research is recommended to discover how moral education could help the goal of sustainable development.

Second, the findings of the study align with Kohlberg's [12] six stages of moral development theory, confirming different levels of complexity among morally challenging real-life business situations. That is, TA professionals, according to the study participants, experience a variety of morally challenging business situations and their ability to resolve such situations are often constrained by the wicked nature of these problems. Industry- and global-level problems are beyond an individual or a firm's control due to cultural differences, societal norms and expectations, and discrepancies in standards for environmental or labor regulations in the global marketplace. The industry's pursuit of speed-to-market and higher margins often pushes companies to manipulate financial reports in order to get ahead of competition and stay in business. With such force from the industry and economic paradigm, without sound and appropriate moral ability, professionals, especially young professionals, may easily act in a morally questionable manner, jeopardizing sustainability of supply chains. The need to prepare current and future professionals for considerate and morally sound decision-making further supports the need for moral development education. Therefore, the study findings have important implications for developing moral education modules in traditional educational settings, as well as in professional development modules in corporate settings.

Third, the findings of the study provide important insights into different shades, or degrees, of morally challenging situations, which often are difficult to determine whether they are clearly right or wrong. These findings will then be able to serve as appropriate and meaningful contexts for future moral education in both academic and professional settings. The complexity spectrum from simple to wicked and from the individual and firm to the industry and global levels of the morally challenging situations informs us that there is a need for educational modules that address shades of morality and levels of consequences of moral judgment, affect, and behavior in TA supply chains. Simpler problems could be learned or taught via traditional context-based learning activities, such as reading case studies or listening to and discussing with others. For more wicked problems, simulation-based learning activities such as role playing, or argumentative strategies such as constructive controversies [32], might be helpful. For both problems, self-reflection would be a critical way to enhance student learning. The collection and classification of real-life industry morally challenging situations, therefore, contribute to the literature and facilitate dialogues toward the development of moral education tools for the different levels of complexities. 
This study is not without limitations. Given the exploratory nature of the study, the findings must be interpreted with caution; they are not recommended to be generalized. Rather, the findings show potential contexts and complexities of morally challenging situations that TA professionals face in everyday settings. Therefore, further empirical research utilizing surveys or other quantitative techniques would help generalize the study findings with the TA supply chain. Furthermore, the study findings do not show how often TA professionals face such morally challenging situations throughout their career. Additional quantitative research would help us gauge the extent of moral ability that might be necessary when professionals navigate their professional lives. The context of the TA industry, which operates from developing countries based on low-wage labor to developed countries based on technology and innovation, is also recommended to be considered when extrapolating the findings to other industries. Consideration of whether or not similar morally challenging situations are common in other industries, such as automobiles or computers, would be useful when developing moral development educational materials. Finally, further research is recommended to assess the extent of business professionals' exposure to such morally challenging situations. That would further validate the need for professional moral development education.

Acknowledgments: This material is based upon work that is supported by the National Institute of Food and Agriculture, U.S. Department of Agriculture, under award number 2017-70003-26392.

Author Contributions: Jung Ha-Brookshire conceived the research idea and was responsible for drafting the paper initially. The rest of the researchers collected a portion of the study data and analyzed the study data collectively. Everyone contributed to editing the manuscript.

Conflicts of Interest: The authors declare no conflict of interest.

\section{References}

1. Cambridge University Press; United Nations. Our Common Future: Report of the World Commission on Environment and Development. 1987. Available online: http:/ /www.un-documents.net/our-commonfuture.pdf (accessed on 20 July 2017).

2. Armstrong, C.; LeHew, M.L.A. Barriers and Mechanisms for the Integration of Sustainability in Textile and Apparel Education: Stories from the Front Line. Fash. Pract. 2014, 6, 59-85. [CrossRef]

3. Dicken, P. Global Shift: Mapping the Changing Contours of the World Economy, 7th ed.; Guilford Press: New York, NY, USA, 2015; ISBN 1609180062.

4. Ha-Brookshire, J.; Hawley, J. Envisioning the Clothing and Textile Discipline for the 21st Century: Discussion on its Scientific Nature and Domain. Cloth. Text. Res. J. 2013, 31, 17-31. [CrossRef]

5. Ha-Brookshire, J. Toward Moral Responsibility Theories of Corporate Sustainability and Sustainable Supply Chain. J. Bus. Ethics 2015. [CrossRef]

6. Hess, K.M. "If you tickle us..." How corporations can be moral agents without being persons. J. Value Inq. 2013, 47, 319-335. [CrossRef]

7. Donaldson, T. Nike Balks at Buying in Bangladesh Despite Margin Pressure. 2014. Available online: https: / / sourcingjournalonline.com/nike-balks-buying-bangladesh-despite-margin-pressure-td/ (accessed on 20 July 2017).

8. Donaldson, T. H\&M Plans to Buy More from Bangladesh. 2014. Available online: https:/ / sourcingjournalonline. com/hm-plans-buy-bangladesh-td/ (accessed on 20 July 2017).

9. Kenneally, I. Walmart Slammed for "Pathetic" Contribution to Rana Plaza Victims Fund: \$2.2 Million. 2014. Available online: https:/ / sourcingjournalonline.com/walmart-slammed-pathetic-contribution-rana-plazavictims-fund-2-2-million/ (accessed on 20 July 2017).

10. Barrow, H.S.; Tamblyn, R.M. Problem-Base Learning: An Approach to Medical Education; Springer: New York, NY, USA, 1980.

11. Huang, W.; Jonassen, D.H.; Liu, R. Problem-based Learning. In Handbook of Research on Educational Communications and Technology; Springer: Berlin, Germany, 2014; Volume 3, pp. 485-506.

12. Kohlberg, L. A current statement on some theoretical issues. In Lawrence Kohlberg: Consensus and Controversy; Modgil, S., Modgil, C., Eds.; Falmer Press: Philadelphia, PA, USA, 1986; pp. 485-546. 
13. Armstrong, C.; LeHew, M.L.A. Scrutinizing the Explicit, the Implicit and the Unsustainable: A Model for Holistic Transformation of a Course for Sustainability. J. Teach. Educ. Sustain. 2011, 13, 17-43. [CrossRef]

14. Leerberg, M.; Riisberg, V.; Boutrup, J. Design Responsibility and Sustainable Design as Reflective Practice: An Educational Challenge. Sustain. Dev. 2013, 18, 306-317. [CrossRef]

15. Anderson, B.G.; LeHew, M.L.A.; Hiller Connell, K.Y.; Sutheimer, S.; Hustvedt, G. Professional Development and Education for Apparel and Textile Educators. 2016. Available online: https://athenas.ksu.edu/ (accessed on 7 July 2017).

16. Dempsey, J. Corporations and Non-agential Moral Responsibility. J. Appl. Philos. 2013, 30, 334-350. [CrossRef]

17. Dubbink, W. A Moral Grounding of the Duty to Further Justice in Commercial Life. Ethical Theory Moral Pract. 2015, 18, 27-45. [CrossRef]

18. Swaner, L.E. Educating for Personal and Social Responsibility: A Review of the Literature. Lib. Educ. 2005, 91, 14-21.

19. Perry, W.G., Jr. Forms of Ethical and Intellectual Development in the College Years: A Scheme, 1st ed.; Jossey-Bass: San Francisco, CA, USA, 1998; ISBN 0787941182.

20. Passarella, E.T.; Terenzini, P.T. How College Affect Students: A Third Decade of Research; Jossey-Bass: San Francisco, CA, USA, 2005; Volume 2, ISBN 0787910449.

21. Hoffman, M.L. Empathy and Moral Development: Implications for Caring and Justice; Cambridge University Press: Cambridge, UK, 2000; ISBN 052158034X.

22. Noddings, N. Educating Moral People: A Caring Alternative to Character Education; Teachers College Press: New York, NY, USA, 2002; ISBN 080774168X.

23. Bandura, A. Social Learning Theory, 2nd ed.; Englewood Cliffs: Prentice Hall, NJ, USA, 1977.

24. Astin, A.W. What Matters in College? Four Critical Years Revisited; Jossey-Bass: San Francisco, CA, USA, 1993.

25. Lapsley, D.K. Moral Psychology; Westview Press: Boulder, CO, USA, 1996.

26. Creswell, J.W. Qualitative Inquiry and Research Design: Choosing among Five Approaches, 3rd ed.; Sage Publications: Thousand Oaks, CA, USA, 2013; ISBN 1412995302.

27. Denzin, N.K.; Lincoln, Y.S. The Sage Handbook of Qualitative Research, 4th ed.; Sage: Thousand Oaks, CA, USA, 2011; ISBN 1412974178.

28. Rittel, H.W.; Webber, M.M. Dilemmas in a General Theory of Planning. Policy Sci. 1973, 4, 155-169. [CrossRef]

29. Conklin, J. Dialogue Mapping: Building Shared Understanding of Wicked Problems; Wiley Publishing: Chichester, UK, 2006; ISBN 0470017686.

30. McGregor, L. Adidas Beats 2015 Better Cotton Target, 2016. Available online: https:/ / sourcingjournalonline. com/adidas-beats-2015-better-cotton-target/ (accessed on 20 July 2017).

31. WWD Staff, Chargebacks Crisis: Saks Inc. to Repay $\$ 21.5 \mathrm{M}$ to Vendors. 2005. Available online: http://wwd. com/business-news / financial/chargebacks-crisis-saks-inc-to-repay-21-5m-to-vendors-581255/ (accessed on 20 July 2017).

32. Morais, T.; Silva, H.; Lopes, J.; Dominguez, G. Argumentative Skills Development in Teaching Philosophy to Secondary School Students through Constructive Controversy: An Exploratory Study Case. Curric. J. 2017, 28, 249-265. [CrossRef]

(c) 2017 by the authors. Licensee MDPI, Basel, Switzerland. This article is an open access article distributed under the terms and conditions of the Creative Commons Attribution (CC BY) license (http://creativecommons.org/licenses/by/4.0/). 